\title{
The NHS is heading down a hole-should we stop digging?
}

\author{
Fiona Godlee editor, BMJ
}

\begin{abstract}
A few weeks ago Martin McKee asked "Does anyone understand the government's plan for the NHS?" (BMJ 2012;344:e399, doi:10.1136/bmj.e399). McKee had three questions: why were the reforms necessary, what exactly did they consist of, and why were changes happening before the legislation has been passed? Emails he received, as well as rapid responses on bmj.com, suggest that many of you share his confusion. So we invited the architect of the reforms, Secretary of State for Health Andrew Lansley, to explain. In his reply (doi:10.1136/bmj.e789) he says the reforms will safeguard the NHS for the future, put patients first, focus efforts on overall results delivered to patients, and empower the public and NHS staff to make local decisions on how services are delivered.
\end{abstract}

This all sounds reasonable. Why then is there so much anger about the changes? Perhaps because, as I and the editors of the Health Service Journal and Nursing Times argue in an editorial published in all three journals this week, the resulting upheaval has been unnecessary, poorly conceived, badly communicated, and a dangerous distraction at a time when the NHS is required to make unprecedented savings. The result, we conclude, is an unholy mess, a bloated and opaque piece of legislation, the goals of which could have been achieved by other means.

Lansley disputes this. He says the legislation is essential to establish the NHS's legal obligation to continuously improve quality of care and reduce health inequalities. The bill will give the new clinical commissioning groups the legal right to commission services (doi:10.1136/bmj.e767), but Lansley says these groups will not be able to delegate their responsibilities or to favour private over public providers. He confirms that the bill will make the NHS "operationally independent" from ministers. In future, he says, "I will not be able to micromanage the daily decisions which should be left to those who are clinically qualified."

The bill is nearing its end stages in the House of Lords, but has it reached the point of no return? Not necessarily, says Kieran Walshe (doi:10.1136/bmj.e 748): if the bill were abandoned now, work on creating the national commissioning board, the health sector regulator Monitor, and the clinical commissioning groups would stop and the transitional structures (the primary care trust clusters and the merged strategic health authorities) would become permanent. These, he argues, would carry on providing healthcare to patients. There are benefits to such a plan, he says. It would end the damaging uncertainty of the past 18 months, it would allow NHS organisations to focus on the urgent challenge of improving efficiency, and it would save about $£ 1$ bn in set up and running costs.

It's a captivating idea but unlikely to happen. In the absence of united opposition, the bill will pass. For the sake of the NHS - arguably one of this country's greatest achievements-we can hope that the outcome will be better than we fear. But our joint editorial concludes that, ironically, Lansley's one great achievement may be reforms designed and implemented so badly that the next government will find it necessary to overhaul the NHS all over again.

Cite this as: BMJ 2012;344:e805

๑ BMJ Publishing Group Ltd 2012 